\title{
Chiropractic treatment as a primary care intervention for better musculoskeletal health in the aging population in the United Kingdom: an opinion and positioning paper
}

\author{
Adrian Hunnisett* and Christina Cunliffe \\ McTimoney College of Chiropractic, Abingdon, Oxfordshire, UK \\ ${ }^{*}$ Correspondence: ahunnisett@mctimoney-college.ac.uk
}

\section{INTRODUCTION}

Many countries, including the UK, find themselves with an increasingly aging population [World Health Organisation (WHO), 2011]. The number of people in the UK aged over 75 is set to double over the next 25 years (ONS, 2011). However there is particular concern regarding the impact on health care provision and demand with debate in the literature concerning the strategies designed to cope with the increased demand such as improved health service performance, redesign, and investment in new treatments (Saltman et al., 2006).

Aging is associated with an increased incidence and risk of developing a wide variety of disease conditions, the most prevalent being the decline in musculoskeletal function. There is a debate around whether the musculoskeletal decline is an aging phenomenon per se, or whether it is a distinct pathological process increasing in risk as the individual ages (Lawrence et al., 1989; Dieppe, 1993).

In addition, muscle mass and function are also reduced with age (Minaker, 2007). Together, the muscle and bone factors are important in the observed increase in frailty and falls risk in the elderly population.

The elderly are generally encouraged to take more exercise to ensure, and maintain, musculoskeletal health, and many healthcare strategies build upon this principle. This paper aims to outline how chiropractic intervention and maintenance programs can play a pivotal role in the health promotion and continued musculoskeletal functioning of the elderly population.

\section{TREATMENT OF THE ELDERLY POPULATION}

Currently, geriatric medicine focuses on developing detailed histories, identifying co-morbidities, current use of medication, and treatment plans (Hulbert et al.,
2005). With musculoskeletal problems management, rather than cure, is considered a more realistic strategy (Waxman et al., 2000).

The aim of chiropractic care in the elderly population is to restore function where possible and to arrest, or at least slow down, the degenerative processes that occur with aging (Souza, 2009). In order to maintain a state of independent living, it is vitally important for the individual to be able to maintain general function for as long as possible. This has a significant effect on perceived quality of life, particularly in the much older age groups (Fleming et al., 1995; Xavier et al., 2003). Additionally, elderly patients who receive chiropractic care in addition to medical care, have fewer hospitalization events and use fewer medications than those receiving traditional medical care alone (Coulter et al., 1996).

\section{CHIROPRACTIC AS AN INTERVENTION}

Chiropractic is an holistic intervention with chiropractic adjustments as the core concept of the treatment (Mootz and Haldeman, 1995). It focuses on relationships between structure and function of the musculoskeletal and nervous systems and how these preserve and restore health. The profession is regulated by statute (Chiropractors Act, 1994) under the auspices of the General Chiropractic Council ${ }^{1}$.

Interventions, such as chiropractic, have become increasingly popular as patients seek options available to them outside traditional medicine (Neuberger, 1998). There is ample evidence that chiropractic is both effective and safe in musculoskeletal conditions, particular in patients with low back pain (Waddell, 1998; UK BEAM Trial Team, 2004). It enjoys high patient satisfaction

'http://www.gcc-uk.org
- important as satisfaction may be related to clinical outcomes (Gemmel and Hayes, 2001; Gaumer, 2006).

Preventive, or maintenance, care is even more important as one grows older (Leboeuf-Yde and Hestbaek, 2008). Since musculoskeletal complaints are generally chronic in nature, maintenance programs seek to avoid acute exacerbations and maintain optimal function (Rupert et al., 2000). Consequently this age-group has a culture of "health promotion and preservation" that makes maintenance alternative health programs a popular adjunct to conventional medicine.

There is controversy surrounding treatment availability to the elderly (Leboeuf-Yde and Hestbaek, 2008). In the UK, chiropractic is a private treatment not available on the National Health Service (NHS) and, therefore, a chargeable service to patients. Lower income groups and the elderly are deterred from chiropractic treatment due to the costs (Manga et al., 1993).

\section{INTEGRATION OF CHIROPRACTIC INTO THE UK NHS}

In the United Kingdom, the NHS is the largest health service that relies on public funding and is government controlled through the Department of Health (DoH). The first point of NHS contact for the majority of the UK population is their General Medical Practitioner (GP), the primary care "gatekeepers" to onward referral into the NHS system.

The health service provision in the UK is publicly funded by the Government through the general taxation system rather than individual personal health insurances. A comprehensive range of health services are provided and the vast majority is free at the point of delivery to residents of the United Kingdom. Subject to residency regulations, healthcare is also provided free of charge to foreign nationals in the UK. Reciprocal services are 
provided throughout the European Union through the European Health Insurance Card system (Gorsky, 2008). This is in contrast to the general provision in countries such as Belgium, France, and Germany where healthcare is paid through a mixture of insurances and government subsidy. In the USA, healthcare is totally funded by private individual healthcare insurance policies with no state subsidy.

This difference in healthcare provision also provides for an element of choice. In a totally private system, the patient is free to choose the type of treatment they may have for a particular condition. This also means that many complementary therapies are well established treatment modalities in countries where healthcare does not have such a high level of government subsidy and gives more patient choice (Cassileth, 1996). This is not so in the UK NHS. Many complementary and alternative therapies are not included in NHS provision and are provided on a privately funded basis with the patient having to pay. This cost element can be a barrier to the integration of certain therapies into the general primary care arena.

The popularity of complementary and alternative medicine (CAM), including chiropractic, has grown over the past few decades. However, despite this growth, chiropractic has failed to lay a foundation of authority and value with the general public preventing integration and acceptance of the chiropractic profession within primary care (Murphy et al., 2008). Since the GP is first contact for most patients, the opinion the GP can have a strong influence over acceptance of chiropractic and also how they deal with the patient referral pathways.

There are three key factors that may facilitate the integration of chiropractic more firmly into primary care and the NHS, namely a proper mechanism for inclusion of chiropractic into "mainstream" NHS, awareness of chiropractic and referral process and, finally, better communication between the medical and chiropractic professions.

\section{MECHANISM OF INCLUSION FOR CHIROPRACTIC}

Over recent years there has been a drive toward primary care services outside a traditional hospital setting (Breen et al., 2000). In response to a finding that almost a third of all GP consultations were for musculoskeletal complaints, the DoH produced the "Musculoskeletal Services Framework" (DoH, 2006). This clearly states "the management of musculoskeletal conditions is multidisciplinary." Chiropractic is specified as a route that patients with joint pain can access without referral from a GP $(\mathrm{DoH}, 2006)$.

The NHS is currently undergoing further reorganization with new primary care commissioning groups made up of local GPs. Chiropractic would be in a position is now able to compete directly for referral business from the NHS and ensure professional viability and sustainability from both NHS funded and privately funded sources. Chiropractors would be well positioned to act as independent service providers, just like GPs, and develop appropriate service level agreements with local commissioning groups to provide musculoskeletal treatment services.

The increase in quality of evidence to support chiropractic and other manual therapies has been acknowledged and appraised by the National Institute for Clinical Excellence (NICE) ${ }^{2}$. NICE issued a specific guidance document for the early management of persistent, non-specific low back pain [NICE, 2009], commending the developments in research for low back pain. It also recognized that non-specific low back pain can be helped by spinal manipulation therapies, specifically chiropractic. NICE emphasizes that "manual therapies" are both clinically effective and cost-effective in the early management of non-specific lower back pain.

The most recent development is the release of the Government White Paper "Equity and Excellence: Liberating the NHS" (DoH, 2010a) and its consultation document "Liberating the NHS: Greater Choice and Control" (DoH, 2010b). Following this, the DoH has released "Operational Guidance to the NHS on Extending Patient Choice of Provider" and this sets out the guidance for the phased implementation of the "Any Qualified Provider" (AQP) initiative (DoH, 2011).

Musculoskeletal services have been identified as one of eight priority service lines for the AQP model, enabling patients to choose, through commissioning routes, $\mathrm{AQP}$ where this will result in improved and better care.

${ }^{2}$ www.nice.org.uk
Chiropractic is one such provider and qualified chiropractors may tender for services under the musculoskeletal service line to provide professional services for neck and back pain. This is crucially good news for the chiropractic profession and provides the most promising route to date for the inclusion of chiropractic into the NHS as an accepted intervention for musculoskeletal health across the whole population, including the elderly.

\section{AWARENESS AND REFERRAL PATTERNS BY GPs}

Previous research and recent guidelines suggest that the knowledge and perceptions of chiropractic held by GPs are changing [British Medical Association General Practitioners Committee (BMA GPC), 2009]. A significant proportion of GPs have either already referred or will, at some point in their careers, refer to chiropractors and other forms of CAM and that a better understanding of the value of research by chiropractors will cause a rise in evidencebased practice (Murphy et al., 2008).

In an analysis of GP non-medical referral patterns, the majority of recommendations (63\%) were for chiropractic or osteopathy (White et al., 1997). It was also concluded that GPs believed that acupuncture, chiropractic, and osteopathy were effective and should be available within the NHS. A further study postulated that the culture of evidence-based medicine has influenced the considerable proportion of GPs who consider the lack of scientific evidence is a reason that CAM therapies should not be offered to patients (Poynton et al., 2006). These and other studies (Greene et al., 2006; Smith et al., 2006) highlight the need for further research into the facilitators and barriers to developing more positive relationships between the professions.

\section{COMMUNICATION BETWEEN PROFESSIONS}

An investigation of drivers and barriers to inter-professional relationships between GPs and chiropractors found that good communication, openness to discussion by providers, and patient interest were identified as key factors for developing positive relationships. Lack of good communication, bias toward alternative medicine, lack of knowledge, or understanding of chiropractic care as well as economic and 
geographic constraints were identified as barriers to good inter-professional relationships (Allareddy et al., 2007). A previous study showed substantial support of referral of musculoskeletal complaints (Jamison, 1995). This study also noted an increased range of conditions deemed suitable for chiropractic referral, suggesting that feedback from the chiropractor on chiropractic care improves GP perception of the scope of practice of chiropractic.

Awareness of chiropractic and it's achievements is essential for the improved inter-professional relationships between GPs and chiropractors. There is a clear lack of education on complementary medicine and chiropractic which needs to be addressed in the undergraduate medical training programs. Patients have an increased awareness of complementary medicine due to media and the internet and it is now in the interest of modern doctors to be informed. A survey of GPs in the South of England showed preference on the part of GPs to refer to physiotherapy, only because they had a better understanding of the treatment involved. Also, the majority of practitioners favored receiving a report when a patient completes treatment, outlining the nature of the treatment, examination findings, and the treatment involved (Breen et al., 2000).

\section{CONCLUSION}

How does chiropractic continue to position itself within a health care system? This is a question that It is not possible to definitively answer here, but there is no doubt that improving communication processes leads to better and more efficient referral practices, regardless of how chiropractic seeks to position itself outside or inside traditional medical practice.

Chiropractors are themselves well positioned to play a pivotal role in the health promotion, disease intervention, and geriatric care strands of primary healthcare. Chiropractic services are safe, health-effective, and cost-effective (Carey et al., 1995) and enjoy high patient satisfaction (Smith and Stano, 1996). Time pressures may preclude allopathic practitioners from spending the time to discuss health promotion and prevention programs adequately, but this is not so with chiropractic. In combination with the hands-on manipulative nature of the care, a strong practitioner-patient relationship is formed in which appropriate health and lifestyle recommendations can be discussed in a comfortable, supportive, and effective way.

A new and exciting mechanism for the advancement of chiropractic into mainstream NHS treatment is emerging. The chiropractic profession is now in one of its best positions to capitalize on this by offering patient-centered care for the management of musculoskeletal disorders. If there is to be equity of health provision, the chiropractic profession should now embrace these current initiatives.

\section{REFERENCES}

Allareddy, V., Greene, B., Smith, M., Haas, M., and Liao, J. (2007). Facilitators and barriers to improving interprofessional referral relationships between primary care physicians and chiropractors. J. Ambul. Care Manage. 30, 347-354.

Breen, A., Carrington, M., Collier, R., and Vogel, S. (2000). Communication between general and manipulative practitioners: a survey. Complement. Ther. Med. 8, 8-14.

British Medical Association General Practitioners Committee. (2009). Referrals to Complementary Therapists Regulated by Statute, Guidance for GPs. Available at: http://www.bma.org.uk/images/refcomtherap0406_tcm41-190153.pdf

Carey, T., Garret, J., and Jackman, A. (1995). The outcomes and costs of care for acute low back pain among patients seen by their primary care practitioners, chiropractors and orthopaedic surgeons. N. Engl. J. Med. 333, 913-917.

Cassileth, B. (1996). Alternative and complementary cancer treatments. Oncologist 1, 173-179.

Chiropractors Act. (1994). Office of Public Sector Information, National Archives. Available at: http://www.opsi.gov.uk/ACTS/acts 1994/ ukpga_19940017_en_1

Coulter, I., Hurwitz, E., Aranow, H., Cassata, D., and Beck, J. (1996). Chiropractic patient in a comprehensive home-based geriatric assessment follow-up and health promotion program. Top. Clin. Chiropr. 3, 46-55.

Department of Health. (2006). The Musculoskeletal Services Framework. Available at: http://www. dh.gov.uk/en/Publicationsandstatistics/Publications/ PublicationsPolicyAndGuidance/DH_4138413

Department of Health. (2010a). Equity and Excellence: Liberating the NHS. London: Department of Health. Department of Health. (2010b). Liberating the NHS: Greater Choice and Control. Department of Health. Available at: http://www.dh.gov.uk/en/Consultations/ Liveconsultations/DH_119651

Department of Health. (2011). Operational Guidance to the NHS on Extending Patient Choice of Provider. Department of Health. Available at: http:// www.dh.gov.uk/en/Publicationsandstatistics/ Publications/PublicationsPolicyAndGuidance/ DH_128455

Dieppe, P. (1993). Strategies for the prevention of osteoarthritis. Tissue React. 15, 93-97.
Fleming, K., Evans, J., Weber, D., and Chulka, D. (1995). Practical functional assessment of elderly persons: a primary care approach. Mayo Clin. Proc. 70, 890-910.

Gaumer, G. (2006). Factors associated with patient satisfaction with chiropractic care: survey and review of the literature. J. Manipulative Physiol. Ther. 29, 455-462.

Gemmel, H., and Hayes, B. (2001). Patient satisfaction with chiropractic physicians in an independent physicians association. J. Manipulative Physiol. Ther. 24, 556-559.

Gorsky, M. (2008). The British National Health Service 1948-2008: a review of the historiography. Soc. Hist. Med. 21, 437-460.

Greene, B., Smith, M., Allareddy, V., and Haas, M. (2006). Referral patterns and attitudes of primary care physicians towards chiropractors. BMC Complement. Altern. Med. 1, 5. doi: 10.1186/1472-6882-6-5

Hulbert, J., Osterbauer, P., Davis, P. T., Printon, R., Goessl, C., and Strom, N. (2005). Chiropractic treatment of hand and wrost pain in older people: systematic protocol development: part 2: cohort natural-history treatment trial. J. Chiropr. Med. 6, 32-41.

Jamison, J. (1995). Chiropractic referral: the views of a group of conventional medical practitioners with an interest in unconventional therapies. J. Manipulative Physiol. Ther. 18, 512-518.

Lawrence, R., Hochberg, M., and Kelsey, J. (1989). Estimates of the prevalence of selected arthritic and musculoskeletal diseases in the United States. Rheumatology 16, 427-441.

Leboeuf-Yde, C., and Hestbaek, L. (2008). Maintenance care in chiropractic - what do we know? Chiropr. Osteopat. 16, 3-9.

Manga, P., Angus, D., and Swan, W. (1993). Effective management of low back pain: it's time to accept the evidence. J. Can. Chiropr. Assoc. 37, 221-229.

Minaker, K. (2007). "Common clinical sequelae of aging," in Cecil Medicine, 23rd Edn, Chapt. 23, eds L. Goldman and D. Ausiello (Philadelphia, PA: Saunders Elsevier).

Mootz, R., and Haldeman, S. (1995). The evolving role of chiropractic within mainstream healthcare. Top. Clin. Chiropr. 2, 11-21.

Murphy, D., Schneider, M., Seaman, D., Perle, S., and Nelson, C. (2008). How can chiropractic become a respected mainstream profession? The example of podiatry. Chiropr. Osteopat. 16, 10-16.

National Institute for Clinical Excellence. (2009). Early management of persistent non-specific low back pain. Clin. Guidel. 88.

Neuberger, J. (1998). Primary care: core values patients' priorities. BMJ 317, 260.

ONS. (2011). 2010 UK Based National Population Projections. Newport: Office of National Statistics.

Poynton, L., Sowell, A., Dew, K., and Egan, T. (2006). General practitioners' attitudes toward (and use of) complementary and alternative medicine: a New Zealand nationwide survey. N. Z. Med. J. 119, 35-44.

Rupert, R., Manello, D., and Sandefuhr, R. (2000). Maintenance care: health promotion services administered to US chiropractic patients aged 65 and older, Part II. J. Manipulative Physiol. Ther. 23, 10-19.

Saltman, R., Dubois, H., and Chawla, M. (2006). The impact of ageing on long-term care in Europe and some potential policy responses. Int. J. Health Serv. $36,719-746$. 
Smith, M., Greene, B., Haas, M., and Allareddy, V. (2006). Intra-professional and inter-professional referral patterns of chiropractors. Chiropr. Osteopat. 14, 12-18.

Smith, M., and Stano, M. (1996). Cost and recurrences of chiropractic and medical episodes of low back care. J. Manipulative Physiol. Ther. 20, 5-12.

Souza, T. (2009). Differential Diagnosis and Management for the Chiropractor, 4th Edn. Boston: Jones and Bartlett Publishers.

UK BEAM Trial Team. (2004). United Kingdom Back Pain Exercise and Manipulation (UK BEAM) randomised trial: cost effectiveness of physical treatments for back pain in primary care. BMJ 329, 1381.
Waddell, G. (1998). The Back Pain Revolution. London: Churchill Livingstone.

Waxman, R., Tennant, A., and Helliwell, P. (2000). A prospective follow-up study of low back pain in the community. Spine 25, 2085-2090.

White,A., Resch, K., and Ernst, E. (1997). Complementary medicine: use and attitudes among GPs. Fam. Pract. 14, 302-306.

World Health Organisation. (2011). First International Age-friendly Cities Conference. Dublin. Available at: http://www.who.int/ageing/en/

Xavier, F., Ferraz, M., Marc, N., Ecosteguy, N., and Moriguchi, E. (2003). Elderly people's definition of quality of life. Rev. Bras. Psiquiatr. 25, 31-39.
Received: 01 March 2012; accepted: 23 March 2012; published online: 10 April 2012.

Citation: Hunnisett A and Cunliffe C (2012) Chiropractic treatment as a primary care intervention for better musculoskeletal health in the aging population in the United Kingdom: An opinion and positioning paper. Front. Physio. 3:87. doi: 10.3389/fphys.2012.00087

This article was submitted to Frontiers in Striated Muscle Physiology, a specialty of Frontiers in Physiology.

Copyright (C) 2012 Hunnisett and Cunliffe. This is an openaccess article distributed under the terms of the Creative Commons Attribution Non Commercial License, which permits non-commercial use, distribution, and reproduction in other forums, provided the original authors and source are credited. 